\title{
A new emergency medicine clerkship program: students' perceptions of what works
}

\author{
MarianneYeung, MD; ${ }^{*}$ Jennifer Beecker, MD; ${ }^{*}$ Meridith Marks, MD, M Ed; ${ }^{* \dagger}$ Janet Nuth, MD; \\ Brian Weitzman, MD; ${ }^{*}$ A. Curtis Lee, PhD; Jason R. Frank, MD, MA Ed
}

\section{ABSTRACT}

Objective: Emergency medicine is an evolving discipline in Canadian medical schools. Little has been published regarding student preferences for emergency medicine training during the clerkship phase of MD programs. We assessed medical students' perceptions of a newly developed emergency medicine clerkship rotation involving multiple learning modalities. The evaluation process included assessment of the rotation's instructional elements and overall educational value.

Methods: The first cohort of medical students to complete this new emergency medicine clerkship was invited to answer a questionnaire just before graduation. Students rated their preferences for components of the rotation using paired comparisons. Open-ended questions explored students' satisfaction with the emergency medicine clerkship as well as perceptions of the rotation's impact on career development.

Results: Of the 94 students in the first clerkship cohort, 81 $(86 \%)$ responded to the survey. Students found the emergency medicine clerkship highly valuable, citing the broad range of cases seen, close supervision, and opportunities to develop clinical assessment, decision-making and procedural skills. Students' curricular preferences were for advanced cardiac life support (ACLS) $(26.4 \%)$, clinical shifts $(20.6 \%)$, supervised clinical shifts $(17.8 \%)$, procedural skills laboratories $(14.8 \%)$, tutorials $(10.8 \%)$ and preceptor-assisted learning sessions (9.8\%).

Conclusion: This new emergency medicine clerkship program incorporated multiple learning methods within a 4-week rotation and was highly rated by students. Although clinical shifts and ACLS were generally preferred activities, students had varying individual preferences for specific learning activities. Multiple learning methods allowed all students to benefit from the rotation. This study makes a compelling case for including an emergency medicine rotation with multiple learning modalities as a core element of clerkship at every medical school.

Keywords: medical student, emergency medicine, clerkship, curriculum, evaluation, learning methods

\section{RÉSUMÉ}

Objectif : La médecine d'urgence connaît un essor dans les facultés de médecine du Canada. Or, peu d'articles ont été publiés au sujet des préférences des étudiants relativement à des stages d'externat en médecine d'urgence dans leurs programmes d'études. Nous avons évalué les perceptions des étudiants en médecine à l'égard d'un nouveau stage d'externat en médecine d'urgence qui a recours à de multiples modalités d'apprentissage. Le processus d'évaluation comprenait l'évaluation des éléments d'apprentissage du stage et de sa valeur éducative globale.

Méthodes : Nous avons invité la première cohorte d'étudiants en médecine à avoir effectué ce stage en médecine d'urgence à répondre à un questionnaire juste avant l'obtention de leur diplôme. Les étudiants ont attribué une cote à leurs préférences relatives aux composantes du stage selon une méthode de comparaisons appariées. Les questions ouvertes portaient sur la satisfaction des étudiants relativement au stage ainsi que leurs perceptions de son impact sur leur développement professionnel.

Résultats : Parmi les 94 étudiants de la première cohorte, 81 (86 \%) ont répondu au questionnaire. Les étudiants ont jugé très utile le stage d'externat en médecine d'urgence en raison de la grande variété de cas traités, d'une surveillance étroite et d'occasions de faire des évaluations cliniques, de développer la prise de décision et de perfectionner les techniques $d^{\prime}$ 'intervention. En matière de programme d'enseignement, les étudiants privilégiaient les soins avancés en réanimation cardiovasculaire (SARC) $(26,4 \%)$, les stages d'immersion clinique $(20,6 \%)$, les stages d'immersion clinique supervisés $(17,8 \%)$, les laboratoires de techniques d'intervention $(14,8 \%)$, les tutoriels $(10,8 \%)$ et les séances d'apprentissage en présence d'un précepteur (9,8\%).

Conclusion : Ce nouveau stage en médecine d'urgence de 4 mois intégrait de multiples méthodes d'apprentissage. Les étudiants lui ont accordé des notes élevées. Bien que leurs préférences aient été pour les stages d'immersion clinique et les stages de formation en SARC, ils ont aussi manifesté leur préférence pour des activités d'apprentissage particulières. Le

From the *Department of Emergency Medicine, and the †Academy for Innovation in Medical Education, Faculty of Medicine, University of Ottawa, Ottawa, Ont.

Submitted Feb. 9, 2009; Revised Jul. 17, 2009; Accepted Aug. 25, 2009

This article has been peer reviewed.

CJEM 2010;12(3):212-9 
stage a été profitable à tous les étudiants grâce aux multiples méthodes d'apprentissage utilisées. Cette étude constitue un argument convaincant en faveur de l'inclusion d'un stage en médecine d'urgence utilisant de multiples modalités d'apprentissage au programme de stages d'externat dans toutes les facultés de médecine.

\section{INTRODUCTION}

Until recently, many academic centres have provided emergency medicine rotations for medical students on an ad hoc or elective basis. In 2007, only one-third of medical schools in the United States provided a mandatory emergency medicine clerkship. There is no standard curriculum within these; however, most North American clerkships include clinical shifts in the emergency department and didactic lectures. Less than half include procedural laboratories or procedural performance expectations of students. ${ }^{1}$ In a 2007 Canadian study, 10 of 14 participating medical schools reported having mandatory emergency medicine rotations. Procedural learning was included in $70 \%$ of programs, and seminars were included in $90 \% .^{2}$ However, student preferences for different learning methods have not been extensively examined, ${ }^{3,4}$ and little has been reported about student perceptions of effective emergency medicine education at the clerkship level.

At the University of Ottawa, the third-year clerkship was redesigned in 2002 to accommodate a larger class size. The Department of Emergency Medicine implemented a new 4-week mandatory block, which began in September 2003. It is well known that students have varying learning styles and preferences; ${ }^{5}$ in designing this rotation, we incorporated multiple learning modalities to optimize the experience for all students.

In this study, we assessed medical students' perceptions of a new design for an emergency medicine clerkship rotation. We explored the relative value of different instructional elements within the rotation and the contribution of this emergency medicine rotation to students' career development. As a program-oriented evaluation, these data provide a source of feedback to assess and modify the rotation if needed. ${ }^{\circ}$

\section{METHODS}

\section{Study design}

We conducted a survey of the first cohort of medical students completing a new mandatory emergency medicine clerkship at either of 2 sites of a 1066-bed, universityaffiliated tertiary care hospital. The written questionnaire was administered in April 2005.

\section{Description of emergency medicine clerkship curriculum}

An undergraduate curriculum planning committee was struck to design the new mandatory 4-week rotation. Committee members included emergency medicine educators (J.N., B.W., J.R.F.), residents and medical students. The committee developed the new program following an extensive literature review search of existing curricula as well as consideration of the recommended models published by the Society of Academic Emergency Medicine..$^{7-9}$ From this, the committee identified 20 core competencies based on CanMEDS roles, 8 procedural skills and 20 core topics to form the basis of the program. We incorporated an extensive range of learning modalities, including the following: scheduled clinical shifts in the emergency department, supervised bedside clinical teaching sessions, procedural skills laboratories, tutorial lectures, preceptor-assisted learning (PAL, student led) sessions, advanced cardiac life support (ACLS) lectures and skills workshops, simulation workshops, a triage shift, and an emergency medical services (EMS) ride-out. (For further descriptions, see Box $1,{ }^{10}$ Table 1, Appendix $1^{10}$ and www.emottawa.ca/site/em _clerkship.shtm). The committee developed overall objectives for the rotation (Appendix 1) and specific objectives for each learning modality. Students and teachers participated in daily formal feedback and evaluation after every learning session and at the completion of the rotation. The newly created program was launched in September 2003.10

\section{Participants}

We invited the participation of the first cohort of $94 \mathrm{stu}-$ dents who completed their mandatory 4-week emergency medicine clerkship rotation from September 2003 to August 2004 at one of 2 sites of our tertiary care hospital. Respondents who completed their required rotation at a third facility were excluded, as their francophone program included significantly different curricular elements $(n=21)$. 


\section{Survey protocol}

We distributed surveys in English and French at a class gathering just before completion of medical school. Students had completed the emergency medicine rotation 8-19 months before participating in the survey. Participation was voluntary, and we obtained informed consent. Participants were asked to evaluate the emergency medicine rotation within the context of their entire 4-year medical school experience.
Responses were received anonymously, and investigators were unaware of the identity of the respondents. The study design was approved by the Ottawa Hospital Research Ethics Board and the Faculty of Medicine, University of Ottawa.

The survey consisted of 2 sections. The first part employed a series of paired comparisons; dyads of 6 selected learning modalities of the emergency medicine clerkship. Students selected the component that they felt best enabled them to achieve the rotation objectives.

Box 1. Clinical objectives of the emergency medicine clerkship (CanMEDS roles) ${ }^{10}$

Role 1: Medical expert

1.1. Perform a focused history and physical exam on a patient

1.2. Be able to generate a differential diagnosis, investigation and treatment plan of the common emergency complaints within the scope of the EM clerkship curriculum

1.3. Place a patient on oxygen (nasal prongs, Venturi mask, rebreather and nonrebreather mask)

1.4. Place a patient on a pulse oximeter, cardiac monitor, interpret a 12-lead ECG

1.5. Start an IV infusion line on a patient

1.6. Insert a nasogastric tube and Foley catheter

1.7. Perform wound cleaning, basic suturing, and bandaging of a simple laceration in a skill lab and on a patient

1.8. Put on a forearm cast and evaluate the extremities for common injuries

1.9. Perform basic and advanced airway maneuvers on a manikin: chin lift, jaw thrust, oral airway insertion, nasal airway insertion, bag-valve mask, orotracheal intubation

1.10. Perform electrical defibrillation, cardioversion and external pacing on a manikin appropriately

1.11. Recognize the common tachycardia, bradycardias, and heart blocks on a monitor

1.12. Recognize myocardial infarction on a 12-lead ECG

\section{Role 2: Communicator}

2.1. Demonstrate effective and empathetic communication with patients and family

2.2. Demonstrate an ability to gather from and provide information to patients and family

2.3. Communicate effectively with other health care providers

\section{Role 3: Scholar}

3.1. Demonstrate an ability to use the various resources available (texts, online resources, searches) for patient care

3.2. Demonstrate an understanding of evidence-based medicine and best practice guidelines and how they relate to patient care in emergency medicine

\section{Role 4: Manager}

4.1. Demonstrate effective use of time for multiple clinical tasks in the ED setting

4.2. Demonstrate cost-effective use of tests for common ED problems

\section{Role 5: Collaborator}

5.1. Establish and demonstrate a professional rapport with other health care workers

5.2. Demonstrate an understanding of the role of allied health care workers in the management of the patient in the ED

5.3. Demonstrates an understanding of when and how other specialties should be consulted

\section{Role 6: Health advocate}

6.1. Recognizes the common conditions and factors underlying ED visits

6.2. Identify opportunities to provide healthy lifestyle choices to patients

6.3. Recognize importance of screening for domestic violence

\section{Role 7: Professional}

7.1. Demonstrate appropriate behaviours worthy of a clinician in the ED setting

7.2. Wear proper attire in the ED

7.3. Demonstrate good charting habits in documentation of the patient record

7.4. Acknowledge own limitations and seek help when appropriate

$\mathrm{ECG}$ = electrocardiogram; $\mathrm{ED}$ = emergency department; $\mathrm{EM}=$ emergency medicine; IV = intravenous 
Review of these comparisons stimulated students' reflections of their rotation as they reported their comparative preferences of learning modalities. Each learning method was presented multiple times within the different dyads, for a total of 15 unique paired comparisons per student. Assessed learning modalities included ACLS training, clinical shifts, supervised clinical teaching sessions, PAL sessions, tutorials and procedural skills/casting laboratories. A copy of the English survey is found in Appendix 1.

The second part of the survey asked learners to respond to the following open-ended questions: "What learning experience(s) in the emergency medicine rotation contributed most to your development as a physician?" "What would you change in the emergency medicine rotation to enhance your learning experience, and why?" and "Any other comments on the emergency medicine rotation?" These open-ended questions permitted a deeper exploration of students' perceptions of the clerkship.

We used both paired comparisons and open-ended questions, as these methods permit differentiation between alternatives that are not easily quantified. The use of complementary methods allowed data to be compared, enhancing the reliability and validity of the results. ${ }^{11}$

\section{Other data sources}

In 2008, the study team was able to secure the Association of American Medical Colleges (AAMC) Canadian Medical
School Graduation Questionnaire for the University of Ottawa for the years 2004-2008. This data provided rankings of rotations by students at the University of Ottawa from the inception of the emergency medicine clerkship.

\section{ANALYSIS}

The results of the paired comparisons were summarized in a comparison table. Descriptive statistics were used to determine the students' preferred learning experiences. ${ }^{12}$ Responses to each open-ended question were collated. We extracted data from these collated responses using an open coding process to identify recurring themes and associations. ${ }^{11}$ Three of the authors (M.Y., J.B., M.M.) independently read and coded the qualitative responses. Discrepancies between the 3 reviewers were resolved by discussion, with review of the collated responses as needed. In developing the final coding structure, particular care was taken to explore contradictory comments and the opinions of outliers, ensuring a range of views were considered in the final analysis. ${ }^{11}$

\section{RESULTS}

\section{Descriptive results}

Overall, 81 of 94 students (86\%) in the first clerkship cohort responded to the survey. A total of 1208 paired

Table 1. Learning modalities provided during the 4-week emergency medicine clerkship rotation

\begin{tabular}{|c|c|c|}
\hline Modality & Description & $\begin{array}{l}\text { Devoted time } \\
\text { during rotation }\end{array}$ \\
\hline Clinical shifts & $\begin{array}{l}\text { Supervised 1:1 by faculty. Students are exposed to a broad range of patients in all } \\
\text { areas of the emergency department. }\end{array}$ & $14 \times 7-9$ h shifts \\
\hline $\begin{array}{l}\text { Supervised clinical teaching } \\
\text { shifts }\end{array}$ & $\begin{array}{l}\text { Small group bedside teaching sessions in the emergency department supervised by } \\
\text { faculty or residents. Students are observed and given feedback on history-taking } \\
\text { and physical examination skills. }\end{array}$ & $7 \times 3$-h shifts \\
\hline Procedural skills lab & $\begin{array}{l}\text { Hands-on session using manikins (lumbar puncture, wound care and suturing, } \\
\text { nasogastric tube, Foley catheter and intravenous insertion) }\end{array}$ & 4-h skills session \\
\hline Casting lab & Supervised casting & 2-h skills session \\
\hline $\begin{array}{l}\text { Advanced cardiac life } \\
\text { support course }\end{array}$ & $\begin{array}{l}\text { Didactic lectures and small group hands-on simulation skills lab on basic and } \\
\text { advanced airway management, dysrhythmias, cardioversion, defibrillation and } \\
\text { transthoracic pacing. This is a full certification course. }\end{array}$ & $\begin{array}{l}2 \times 2 \text {-h lectures } \\
8 \text {-h skills session }\end{array}$ \\
\hline Triage shift & Supervised $1: 1$ by triage nurse & 2-h session \\
\hline EMS ride-out & Supervised by paramedic staff & 8-h session \\
\hline Tutorials & $\begin{array}{l}\text { Lectures on } 5 \text { core topics: arrhythmias, abdominal pain, chest pain, toxicology and } \\
\text { trauma. }\end{array}$ & $5 \times 2.5-h$ sessions \\
\hline Preceptor-assisted learning & $\begin{array}{l}\text { Student-led sessions with supervision by faculty or resident on } 15 \text { core topics: } \\
\text { asthma/COPD, shock, headache, hypothermia, burns, anaphylaxis, animal bites, } \\
\text { delirium, seizures, domestic abuse, street drugs, syncope, back pain, } \\
\text { communicating bad news, acute pain control. }\end{array}$ & $4 \times 2.5-h$ sessions \\
\hline
\end{tabular}


comparisons were collected. Four respondents did not complete the comparison of ACLS training versus clinical shifts; all 4 students identified ACLS training and clinical shifts as being their 2 most preferred learning activities. The order of preference for learning activities provided during the rotation was as follows: ACLS (26.4\%), clinical shifts (20.6\%), supervised clinical shifts (17.8\%), procedural skills laboratories (14.8\%), tutorials (10.8\%) and PAL sessions (9.8\%) (Fig. 1).

\section{Qualitative data}

The emergency medicine rotation, as a whole, was repeatedly identified as being "excellent" by students. Comments reflecting this opinion included the following:

- "excellent rotation; all learning opportunities were beneficial"

- "the best rotation of clerkship"

- "Thank you for an excellent rotation. I have decided to pursue emergency medicine ... this is a major shift for me, and a large part was based on this rotation."

Qualitative analysis of the open-ended questions identified 3 primary themes:

1.Learners identified the emergency medicine rotation as providing an outstanding venue to develop clinical assessment and decision-making skills. For many, this was their first opportunity to see a clinical case through to completion, an option that cannot be provided in many clerkship rotations: "[There were] many chances in each shift to work on a concise, focused history, physical exam, differential diagnosis and plan."

2.Learners placed high value on exposure to the great variety of cases and clinical experiences available in the emergency department. Hands-on learning was particularly noted: "[There was a] wide range of

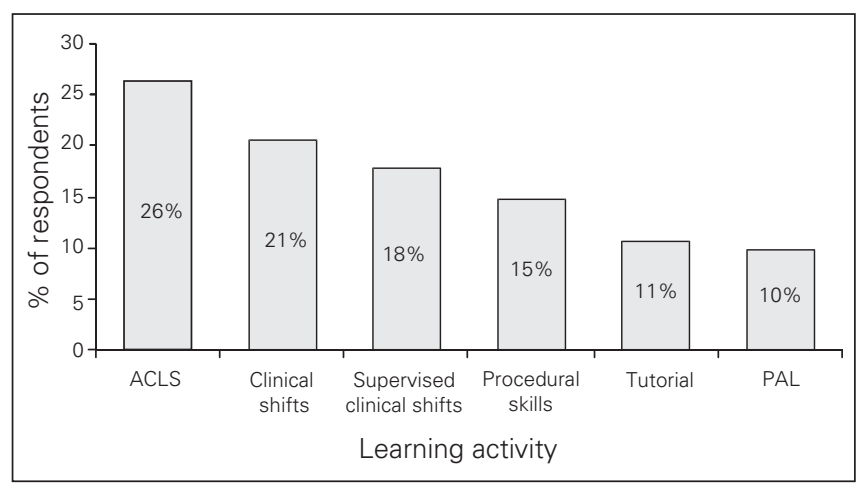

Fig. 1. Paired comparisons: "Which did you find to be the more valuable learning experience?" ACLS = advanced cardiac life support; PAL = preceptor-assisted learning. urgent and emergent cases, with good on-the-spot feedback on physicals and management." "This is one of the best learning experiences in clerkship - especially for hands-on procedural learning."

3. Students appreciated being able to work closely with emergency medicine preceptors, allowing multiple occasions for feedback and evaluation: "Residents and staff were welcoming and allowed much hands-on (supervised) procedural learning." "[There was] lots of 1:1 time with staff to discuss patients and management plans."

Overall, students identified this rotation as having outstanding relevance, even if their future career plans did not include emergency medicine. Many students offered comments ranking this new emergency medicine rotation very highly compared with established clerkship rotations: "This rotation was by far the best learning experience in clerkship."

\section{Proposed changes}

The majority of students wanted no curriculum alterations. Of those who suggested changes, the most frequent requests were for even more emergency medicine exposure, either by lengthening the rotation from 4 to 6 weeks or adding more clinical shifts.

When asked an open-ended question as to which learning experience(s) had contributed most to their physician development, students identified the learning modalities in a similar order as when responding to the paired comparisons (Table 2). Five students found all components equally valuable. Overall, the clinical emergency department shifts were deemed most useful. Supervised clinical teaching shifts attracted the most divergent responses; 13 students favoured them, 5 requested fewer sessions and 5 felt that these shifts would benefit from more structure.

\begin{tabular}{|c|c|c|}
\hline Ranking & Paired comparisons* & Open-ended questiont \\
\hline 1 & ACLS training & Clinical shifts \\
\hline 2 & Clinical shifts & ACLS training \\
\hline 3 & Supervised clinical shifts & Supervised clinical shifts \\
\hline 4 & Procedural sills & Procedural sills \\
\hline 5 & Tutorials & Tutorials \\
\hline 6 & PAL sessions & PAL sessions \\
\hline
\end{tabular}




\section{Other data source}

Data from the AAMC indicated that the graduating medical students at the University of Ottawa ranked emergency medicine first among 10 clinical clerkship rotations for the 5 years examined. Since its introduction, students have given the emergency medicine rotation the highest mean score for quality of educational experience of all the clinical clerkship rotations. ${ }^{13}$

\section{Limitations}

Students were invited only once to complete the survey, at a class gathering. Of the 94 students, 13 (13.8\%) did not respond to the survey. It is possible that the nonrespondents were simply not present on the day of survey distribution; however, there may have been other reasons for nonparticipation leading to responder bias.

This study was limited to the assessment of students' perceptions of their learning. We did not objectively assess which modalities were most effective at imparting new skills or behaviours. We chose to assess the most resource-intensive learning modalities, those facilitated by physicians. The EMS ride-out with paramedics and triage shift with nursing staff were not evaluated in this study.

Our study is limited to one university. Outcomes at other programs may be influenced by various local factors, such as quality of facilitators, case mix and students' prior learning experiences.

\section{DISCUSSION}

The final-year medical students rated this emergency medicine clerkship rotation as highly successful and effective. Few other emergency medicine programs provide students with the opportunity to experience such a broad range of learning activities within a 4-week rotation. Although students had completed this rotation during their third year, this study shows that their positive perceptions of the emergency medicine rotation were sustained throughout their entire clerkship, up to 19 months after their emergency medicine experience. Moreover, the effect was reflected in AAMC scores for the past 5 years which indicated that University of Ottawa graduating medical students have ranked emergency medicine first among 10 clinical clerkship rotations for the 5 years examined.

There is ongoing debate about the best design for clinical clerkships. Most support the use of learnercentred active learning to support systematically designed programs. ${ }^{14}$ Exposure to patients has been repeatedly identified as an important element of clinical rotations, but this exposure alone does not guarantee learning; ${ }^{15}$ hence the need for varied learning modalities. A 2007 survey revealed many discrepancies among Canadian emergency medicine clerkships. ${ }^{2}$ Some universities do not include emergency medicine in their clerkships; in those that do, training in emergency medicine varies from 2 to 4 weeks' duration. Two schools only provide elective experiences. Clinical shifts form the core of all emergency medicine clerkships; however, the number and type of supplementary learning experiences differ greatly from school to school.

Students in this initial cohort of a new emergency medicine clerkship favoured more active learning methods over more passive methods. In the paired comparisons, students ranked ACLS training as the most valuable learning experience, whereas in response to an open-ended question, clinical shifts were identified as the most significant contributor to physician development. The paired comparison between ACLS training and clinical shifts revealed $69.7 \%$ preferred ACLS training. This is not surprising given that ACLS is a time-limited, hands-on activity that has direct relevance to clinical care. Clinical shifts, with their real-world environment, were rated most valued overall throughout the comments. Students appreciated the volume and range of clinical scenarios encountered on every clinical shift; here they gained the most practical experience. Many highlighted the multiple opportunities to develop skills in focused history-taking, physical examination, formulation of differential diagnoses and management plans. The emergency department may be the first place students feel autonomy for patient care, which requires rapid decisionmaking and synthesis of information and also fosters a sense of responsibility and accountability. ${ }^{16,17}$

It is important to note that although ACLS training and clinical shifts were most commonly identified as preferred learning modalities, more than $50 \%$ of learners identified alternate learning activities (Fig. 1). Supervised clinical teaching shifts were the most controversial aspect of the curriculum; equal numbers of students requested additional sessions as requested fewer or more structured shifts. These sessions provide protected teaching time for 3-5 students with 1 teacher. Structure and content are variable and may include observed histories and physicals, informal discussion of clinical cases and emergency medicine topics, observation of major resuscitation cases, radiology and electrocardiogram interpretation, as decided by the supervisor and students.

The more didactic rotation components, namely 
tutorials and PAL seminars, were least favoured. These activities do allow for concentrated and relatively standardized teaching of key emergency medicine subjects that may not be covered in other venues. Interestingly, these teaching sessions are rated much higher immediately after the rotation. ${ }^{18}$ Learning opportunities that provide feedback to students, such as simulation teaching sessions, show less decay of skills over time. ${ }^{19}$ This may explain why active learning activities tended to be rated higher than passive learning sessions when evaluated up to 19 months after completion. It is also worth noting that the tutorials and PAL sessions were each identified as the preferred activity by $10 \%$ of learners.

The strength of this emergency medicine clerkship rotation is not because of any one specific learning activity. Rather, it is the variety of learning activities that all students experience that make the program so valuable. As previously documented, learning preferences vary by individual and the task being addressed. ${ }^{5}$ Multiple modalities allow all students to use their preferred learning styles at different times during the rotation, while receiving a well-rounded exposure to varied patient presentations. In addition to the acquisition of skills in managing acute medical conditions, refinement of history and physical examination skills, time management and clinical reasoning are all further developed through this emergency medicine clerkship program. Student preferences can be used as a guide when apportioning time and resources to different learning activities within a rotation. Based on these results, however, multiple learning interventions should be included. More detailed program evaluation could assess student knowledge and practice behaviours.

\section{CONCLUSION}

This new emergency medicine clerkship program incorporated multiple learning methods within a 4-week required rotation and was highly rated by learners. Although clinical shifts and ACLS training were ranked most highly, the majority of students preferred one of the other learning activities. Multiple learning methods allowed all students to use their preferred learning methods and benefit from the rotation. This study makes a compelling case for incorporating multiple learning modalities in an emergency medicine clerkship at every medical school.

Competing interests: None declared.

\section{REFERENCES}

1. Wald DA, Manthey DE, Kruus L, et al. The state of the clerkship: a survey of emergency medicine clerkship directors. Acad Emerg Med 2007;14:629-33.

2. Frank JR, Penciner R, Upadhye S, et al. State of the nation: a profile of Canadian EM clerkships 2007 [abstract]. CJEM 2008;10:266.

3. Lawrence SL, Lindemann JC, Gottlieb M. What students value: learning outcomes in a required third-year ambulatory primary care clerkship. Acad Med 1999;74:715-7.

4. Antommaria AH, Firth SD, Maloney CG. Evaluation of an innovative pediatric clerkship structure using multiple outcome variables including career choice. 7 Hosp Med 2007;2:401-8.

5. Curry L. Cognitive and learning styles in medical education. Acad Med 1999;74:409-13.

6. Wilkes M, Bligh J. Evaluating educational interventions. BM7 1999;318:1269-72.

7. Liaison Committee on Medical Education. LCME accreditation standards. 2008. The Association of American Medical Colleges and the American Medical Association. Available: www.lcme.org /functionslist.htm (accessed 2008 Dec. 8).

8. Burdick WP, Jouriles NJ, D'Onofrio G, et al.; SAEM Undergraduate Education Committee. Emergency medicine in undergraduate education. Acad Emerg Med 1998;5:1105-10.

9. DeBehnke DJ, Restifo KM, Mahoney JF, et al.; SAEM Undergraduate Education Committee. Undergraduate curriculum. Acad Emerg Med 1998;5:1110-3.

10. Weitzman B, Nuth J, Frank JR, et al. 2003. Department of Emergency Medicine 3rd year clerkship goals and objectives. Ottawa (ON): Department of Emergency Medicine, University of Ottawa Faculty of Medicine. Available: http://vista4.uottawa .ca/webct/cobaltMainFrame.dowebct? appforward=/webct /startFrameSet.dowebct\%3Fforward=organizer_generalFrom CourseChannelList\%26lcid=107666266001 (accessed 2005 Jan. 13).

11. Strauss A, Corbin J. Basics of qualitative research. Thousand Oaks (CA); Sage Publications; 1998.

12. Gravetter FJ, Wallnau LB. Statistics for the behavioural sciences, 7th edition, Toronto (ON): Wadsworth Learning Inc.; 2006.

13. Association of American Medical Colleges, Division of Medical Education. Canadian Medical School Graduation Questionnaire. Ottawa (ON): University of Ottawa Faculty of Medicine; 2008.

14. Curry RH, Hershman WY, Saizow RB. Learner-centred strategies in clerkship education. Am J Med 1996;100:589-95.

15. Fung CC, Relan A, Wilkersion L. Demystifying "learning" in clinical rotations: Do immersive patient encounters predict achievement on the CPX? Acad Med 2007;82(Suppl):S97-S100.

16. Coates WC. An educator's guide to teaching emergency medicine to medical students. Acad Emerg Med 2004;11:300-6.

17. Coates WC. The emergency medicine subinternship - an educator's guide to planning and administration. Acad Emerg Med 2005;12:129.e1-4.

18. Nuth J, Weitzman B, Frank J. An evaluation of a new emergency medicine clerkship [abstract]. CJEM 2009;11:268.

19. Issenberg SB, McGaghie WC, Petrusa ER, et al. Features and uses of high-fidelity medical simulations that lead to effective learning: a BEME systematic review. Med Teach 2005;27:10-28.

Correspondence to: Dr. Marianne Yeung, Emergency Department, The Ottawa Hospital, Civic Campus, 1053 Carling Ave., Ottawa ON K1Y 4E9; myeung@ottawahospital.on.ca 


\section{Appendix 1. Survey on the emergency medicine clerkship rotation ${ }^{10}$}

You are a member of the first class to experience the University of Ottawa Emergency Medicine Clerkship Rotation. We would like to learn your opinions of this rotation.

We hope to use the results of the following survey to evaluate and further develop the curriculum for future students. There is a possibility that this information may be published and therefore we would like to ask for your consent. Your completion of this form will imply your consent. All surveys and answers to the questions will be kept anonymous.

Listed below are some of the objectives for the emergency medicine clerkship rotation. We are interested in how effective the different components of the emergency medicine rotation are at meeting these objectives.

The student will be able to:

1. Perform an accurate and concise history and physical exam in the patient with an undifferentiated presenting to the emergency department (patients whose diagnosis is not yet established).

2. Generate a differential diagnosis, investigation and management plan for undifferentiated patients with common emergency presentations (chest pain, dyspnea, abdominal pain, altered level of consciousness, etc.).

3. Describe the concept of simultaneous patient evaluation and management.

4. Distinguish seriously ill or injured patients from those with minor conditions.

5. Demonstrate an understanding of the concept of triage and prioritization of care.

6. Demonstrate proficiency in basic patient care and procedures.

7. Become proficient in basic wound management.

8. Demonstrate novice proficiency in basic and advanced airway management.

9. Be able to recognize and treat the common dysrhythmias.

10. Demonstrate proficiency in recognizing and treating the patient in cardiac arrest.

11. Understand the concepts of evaluating the multiple trauma patient.

We are interested in determining how effective the different components of the emergency medicine rotation are at meeting these objectives.

Reflecting back on your experiences during the emergency medicine portion of your clerkship training, please comment on which components of the rotation were the best at meeting the learning objectives.

Please circle the activity you preferred:

A. Which did you prefer (i.e., find to be a more valuable learning experience):

1. ACLS training

OR Clinical shifts (regular workday shift)

2. Clinical shifts

OR Supervised clinical teaching sessions (1 staff dedicated to 3-5 students)

3. PAL sessions (where students present emergency medicine topic to their peers and 1 staff preceptor)

OR Clinical shifts (regular workday shift)

4. Tutorials /lectures

5. ACLS training

OR Supervised clinical teaching sessions (1 staff dedicated to 3-5 students)

6. Tutorials/lectures

OR PAL sessions (where students present emergency medicine topic to their peers and 1 staff preceptor)

7. Suturing, lumbar puncture, NG, Foley and casting skills

OR Clinical shifts (regular workday shift)

OR Supervised clinical teaching sessions (1 staff dedicated to 3-5 students)

8. ACLS training

OR Supervised clinical teaching sessions (1 staff dedicated to 3-5 students)

9. Clinical shifts (regular workday shift)

10. Suturing, lumbar puncture, NG, Foley and casting skills

11. Tutorials/lectures

OR Suturing, lumbar puncture, NG, Foley and casting skills

OR ACLS training

OR PAL sessions (where students present emergency medicine topic to their peers and 1 staff preceptor)

12. Suturing, lumbar puncture, NG, Foley and casting skills

13. PAL sessions (where students present emergency medicine topic to their peers and 1 staff preceptor)

OR Tutorials/lectures

OR Suturing, lumbar puncture, NG, Foley and casting skills

14. ACLS training

15. PAL sessions (where students present emergency medicine topic to their peers and 1 staff preceptor)

OR Tutorials/lectures

OR Supervised clinical teaching sessions (1 staff dedicated to 3-5 students)

B. What learning experience(s) in the emergency medicine rotation contributed most to your development as a physician?

C. What would you change in the emergency medicine rotation to enhance your learning experience and why?

D. Any other comments on the emergency medicine rotation?

ACLS = advanced cardiac life support; $N G$ = nasogastric tube; $P A L=$ preceptor-assisted learning 